Aerospace Science and Technology, Volume 92, Issue September, 2019, pp. 839-846

DOI: $10.1016 /$ j.ast.2019.07.013

\title{
Computational Investigations into Heat Transfer over a Double Wedge in Hypersonic Flows
}

\author{
Diego Expósito, ${ }^{*}$ Zeeshan A. Rana* Corresponding author \\ Center for Computational Engineering Sciences, Cranfield University, \\ Cranfield, Bedfordshire MK43 OAL, United Kingdom
}

\begin{abstract}
Recently developed OpenFOAM application hy2FOAM is employed to predict the aerodynamic heat transfer numerically and compared with the experimental data from the University of Illinois. Mach 7 nitrogen flow at 2.1 $\mathrm{MJ} / \mathrm{kg}$ stagnation enthalpy, and Mach 7 nitrogen and air flows at $8 \mathrm{MJ} / \mathrm{kg}$ stagnation enthalpy over a double wedge geometry have been reproduced numerically assuming chemical and thermal non-equilibrium. Good agreement of mean heat transfer profiles has been observed, although none of the simulations achieved a steady-state. The reattachment heat transfer peak in the high enthalpy air case showed an improved agreement with the experimental data, which is due to the non-equilibrium in the flow field.
\end{abstract}

Keywords: Heat transfer, Hypersonic flow, Double wedge, CFD, Boundary layer interactions, High enthalpy flow 


\section{Introduction}

Hypersonic flows challenge our best engineering capabilities and remain one the most demanding problems to reproduce numerically. Computational fluid dynamics (CFD) studies for hypersonic flows aim to accurately predict

5 the aerodynamics as well as strong heat transfer mechanisms that take place on such high-speed vehicles. The aerodynamic heat transfer can be a result of shock-wave boundary layer interactions (SWBLI) which can lead to adverse temperature gradients, strong enough to compromise the vehicles' structural integrity. The study of MacCormack and Baldwin [1] numerically reproduced calorically perfect air at Mach 2, which was then improved by Hung and MacCormack [2] to match the experimental results of Holden [3]. Rudy et al. [4] included three-dimensional effects to improve the agreement between the experiment and the simulations.

Recent research within this field focuses on improving the accuracy of the simulations for heat transfer predictions, where $[5,6,7,8,9,10,11,12,13]$ are selected examples. Due to the complex nature of flow structures arising from shock-wave interactions with the boundary layers and vehicle structure, most fundamental research in this area focuses on canonical geometries. The NATO Advisory Group for Aerospace Research and Development (AGARD) 20 Working Group 10 [14] used axisymmetric geometries (biconic and hollowcylinder flare) to assess the effect of advanced turbulence models on the solution of Mach 2.3 to 5 flows. Perfect gas equations were used, and the wall heat transfer peaks were overpredicted in all geometries.More accurate heat transfer solutions were achieved by NATO RTO AVT Task Group 136 25 [15], where two supersonic flows at $5.38 \mathrm{MJ} / \mathrm{kg}$ (Run 40) and 9.17 MJ/kg 
(Run 42) stagnation enthalpies over a double cone were considered, using thermal and chemical non-equilibrium models. Although the heat transfer prediction of Run 42 showed good agreement with the experimental data, all the CFD solutions featured a transient flow of the steady state experiment for Run 40, the reasons for which are largely unknown.

NATO STO AVT Task Group 205 [16] investigated hyper-velocity flow over a double wedge geometry at 2.1 and $8 \mathrm{MJ} / \mathrm{kg}$ stagnation enthalpies, in an attempt to match the 2D heat transfer measurements of Swantek and Austin [17] using state-of-the-art CFD solvers. This geometry is particularly challenging to investigate computationally due to the high level of thermal non-equilibrium that arises. Their time-resolved simulations did not reach steady-state solutions and several studies produced differing results amongst them, however, agreement of the wall heat transfer profiles with the reference data was deemed qualitatively accurate. The researchers who contributed to this study include Komives et al. [18], Badr and Knight [19], Patil et al. [20] and Durna et al. [21]. In Komives et al. [18], a three-dimensional calculation of the case was performed to 50 flow-times where strong three-dimensional effects at the separation region were observed; however, a very high CFL number of 100 was used in this work, and the results are not considered time-accurate. Although the study of Levin and Tumuklu (see Knight et al. [16]) also suggested that there might be important spanwise effects, there is not enough experimental information to confirm this and modern studies still focus on 2D simulations. The study of Khraibut and Gai [22] achieved steady-state solutions beyond experimental test times for the $8 \mathrm{MJ} / \mathrm{kg}$ cases, and although good agreement is obtained with both nitrogen and air, the 
reattachment heat transfer peak was under-predicted.

The study from Badr and Knight [19] used explicit time integration to solve equilibrium Navier-Stokes equations. Durna et al. [21] reproduced the low enthalpy nitrogen case of this experiment and Khraibut and Gai [22] chose a time-step such that $C F L=20$. The work presented here provides a more in-depth numerical analysis of the same experiment [17] where the novelty is in the numerical reproduction of the experiment in a timeaccurate manner considering chemical and thermal non-equilibrium flow. In addition to this, a time-step of one order of magnitude lower than the stateof-the-art has been employed to ensure the restriction of $C F L<1$ is always achieved. We employed an OpenFOAM [23] application, hy2FOAM, which has been recently developed by Casseau et al. [24, 25] and allows the calculation of non-equilibrium hyper-velocity effects. The code has been validated against reference data which includes results from the LeMANS (The Michigan Aerothermodynamic Navier-Stokes) code [26, 27].

\section{Methodology}

\subsection{Models}

The Knudsen number for this experiment [17] is of the order of $10^{-4}$, so the flow can be assumed continuous. Non-equilibrium, two dimensional NavierStokes equations will be used. More information about the mathematical models used by hy2FOAM can be found in [28]. We attempt to reproduce the low enthalpy nitrogen case (hereafter named as N2) and the high enthalpy nitrogen and air cases (hereafter named as N8 and A8 respectively). A two species $\left(\mathrm{N}_{2}, \mathrm{~N}\right)$ thermochemistry model is employed in this investigations for 
nitrogen ( $\mathrm{N} 2$ and N8) cases, and five species $\left(\mathrm{N}_{2}, \mathrm{~N}, \mathrm{O}_{2}, \mathrm{O}, \mathrm{NO}\right)$ are considered for the air (A8) case. The rotational and vibrational energies are assumed to be in equilibrium with translational and electronic energies respectively, therefore a separate equation is employed to model the vibrational energy. The Landau-Teller [29] model is considered for the energy exchange between both modes. The inter-species relaxation time is taken from Millikan and White [30]. As in most previous studies [16], we assume the flow to be laminar due to the low Reynolds number $\left(\operatorname{Re} \sim 10^{3}-10^{4}\right)$.

The chemical reactions are modeled using the Arrhenius equation with the rates from Park [31] and are considered as irreversible reactions for the N2 case to enhance convergence. Coupling between vibrational energy and chemical reactions is achieved with Park's Two Temperature model [32]. The rule of Wilke [33] is used as mixing law with the correction of Armaly and Sutton [34], together with the fits from Blottner et al. [35] for viscosity coefficients and Eucken's relation [29] for thermal diffusion coefficients.

OpenFOAM's rhoCentralFoam solver determines the numerical scheme used by the application, which is a segregated finite-volume method that calculates the fluxes with the central-upwind scheme of Kurganov et al. [36] (KNP), where the van Leer limiter has been used for reconstruction as recommended in [37]. Although time integration is performed with an implicit first-order Euler scheme, the CFL number must be lower than 0.5 to meet the stability limit required for central schemes. This, together with the explicit solution implemented by Greenshield et al. [37] to solve the inviscid terms, makes rhoCentralFoam what is generally called an "explicit" solver, which has first-order accuracy in time and second-order accuracy in space. The 


\begin{tabular}{ccc}
\hline Point & $x(\mathrm{~m})$ & $y(\mathrm{~m})$ \\
\hline $\mathrm{I}$ & -0.0095 & 0 \\
$\mathrm{O}$ & 0 & 0 \\
1 & 0.044 & 0.0254 \\
2 & 0.0586 & 0.0462 \\
3 & 0.0776 & 0.0462 \\
$\mathrm{P}$ & 0.0505 & 0.1200 \\
\hline
\end{tabular}

Table 1: Location of the points used to define the computational domain. experimental time. The experimental heat transfer measurements were timeaveraged from the viscous establishment time until the test time and achieved an uncertainty of $\pm 8 \%$ of the mean values. 


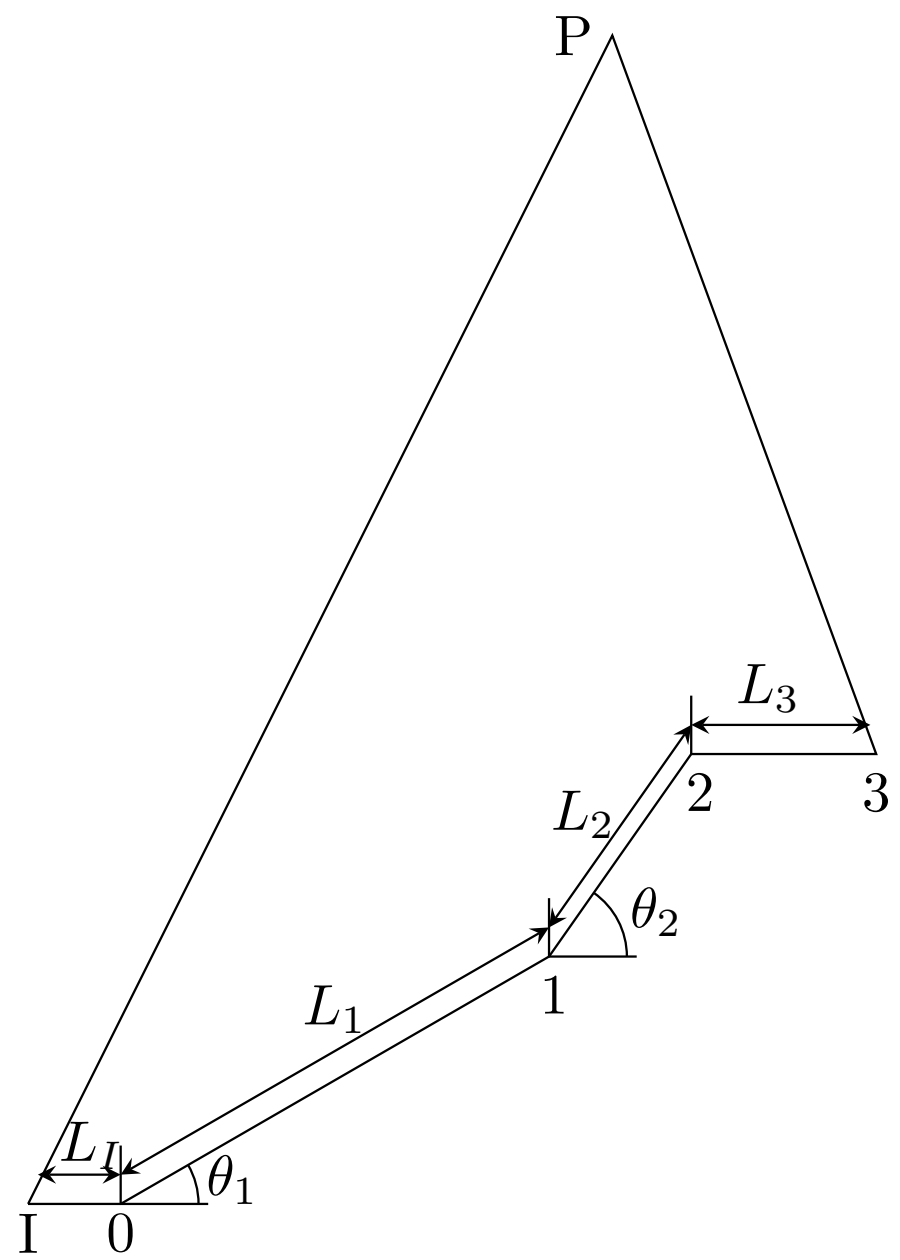

Figure 1: Computational domain used for all cases. 


\begin{tabular}{ccc}
\hline Freestream parameter & Low enthalpy & High enthalpy \\
\hline Mach number & 7.11 & 7.14 \\
Static temperature, K & 191 & 710 \\
Static pressure, $\mathrm{kPa}$ & 0.391 & 0.780 \\
Velocity, m/s & 1972 & 3812 \\
Density, $\mathrm{kg} / \mathrm{m}^{3}$ & 0.007 & 0.004 \\
Test time, $\mu \mathrm{s}$ & 327 & 242 \\
Unit Reynolds number, $10^{6} / \mathrm{m}$ & 1.1 & 0.44 \\
Stagnation enthalpy, $\mathrm{MJ} / \mathrm{kg}$ & 2.1 & 8.0 \\
\hline
\end{tabular}

Table 2: Freestream conditions used in the simulations. corresponding experimental test time. 

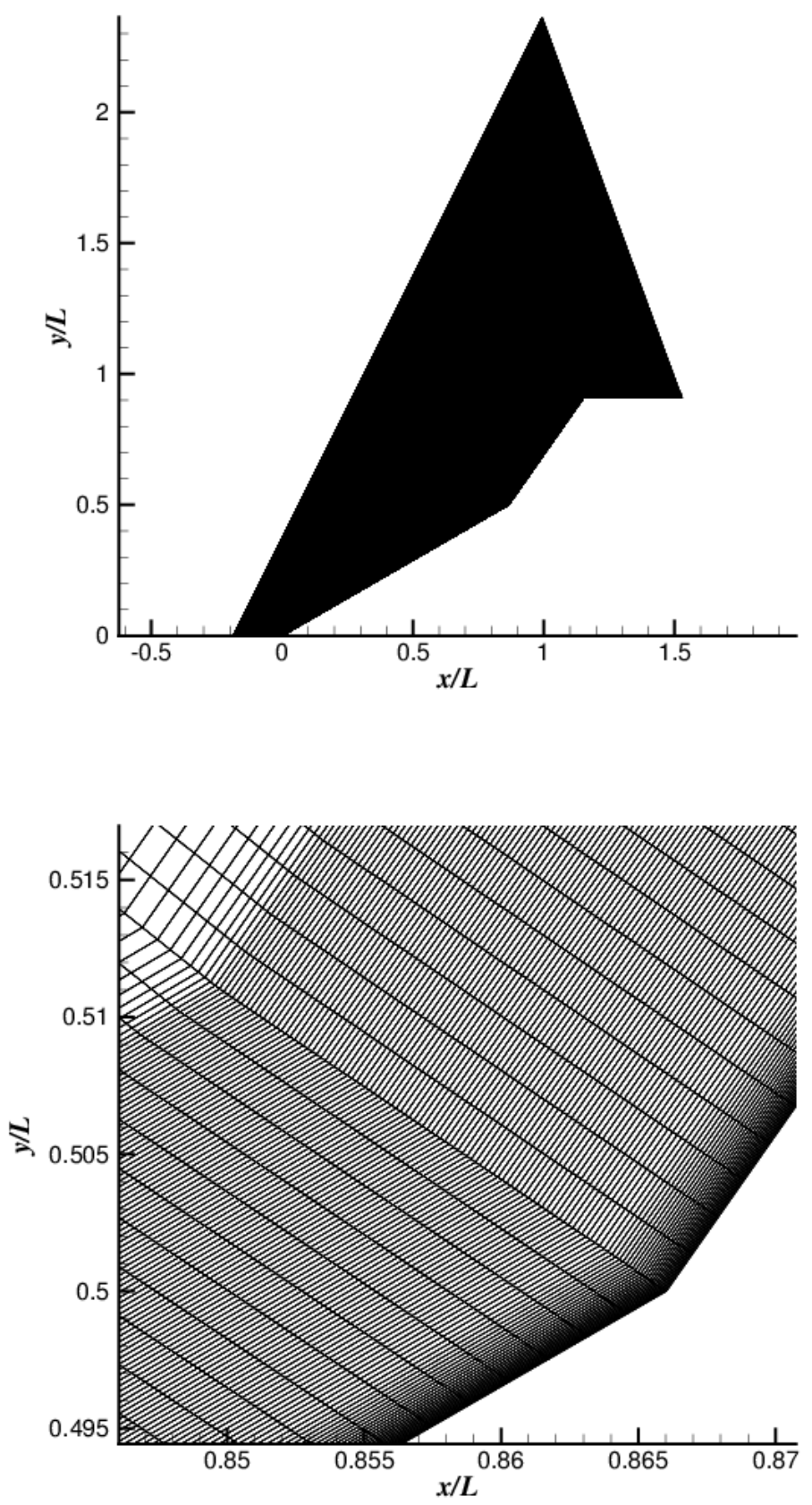

Figure 2: Full view of Mesh 5 (top) and close view of Mesh 5 (bottom) showing the stretching of elements towards the wall. 


\begin{tabular}{ccccc} 
& $N_{x}$ & $N_{y}$ & $N / 10^{5}$ & $\Delta s(\mu \mathrm{m})$ \\
\hline Mesh 3 & 833 & 317 & 3.09 & 4 \\
Mesh 5 & 1136 & 506 & 5.74 & 2.93 \\
Mesh 10 & 1512 & 673 & 10.18 & 2.2
\end{tabular}

Table 3: Mesh parameters, where $\Delta s$ is the first cell height.

\section{Results and discussion}

\subsection{Mesh Convergence}

In order to assess the accuracy of the results, we first compare the solutions obtained by each one of the meshes. Figure 3 provides the separation and reattachment points evolution with time together with the integral surface heat transfer over the geometry, defined as:

$$
Q_{I}(t)=\int_{0}^{L} Q(x, t) d l \approx \sum_{i=1}^{N} Q\left(x_{i}, t\right) \Delta l_{i}
$$

where $l$ follows the direction of the wall. A steady solution of the integrated heat transfer is obtained after $50 \mu$ s, however separation keeps moving upstream while reattachment remains more or less in the same position along time. This trends are very similar in all cases, so we will time-average our results from $t_{a}=50 \mu$ s to the test time, $t_{b}$.

Figure 4 gives the time-averaged heat transfer and shear stress profiles from $50 \mu$ s to $327 \mu \mathrm{s}$. The main differences are obtained at the reattachment heat transfer peak, where Mesh 10 provides the highest value closely followed by the one from Mesh 5. We can assume that mesh convergence has been obtained, and we will use the latter for the rest of the cases. 

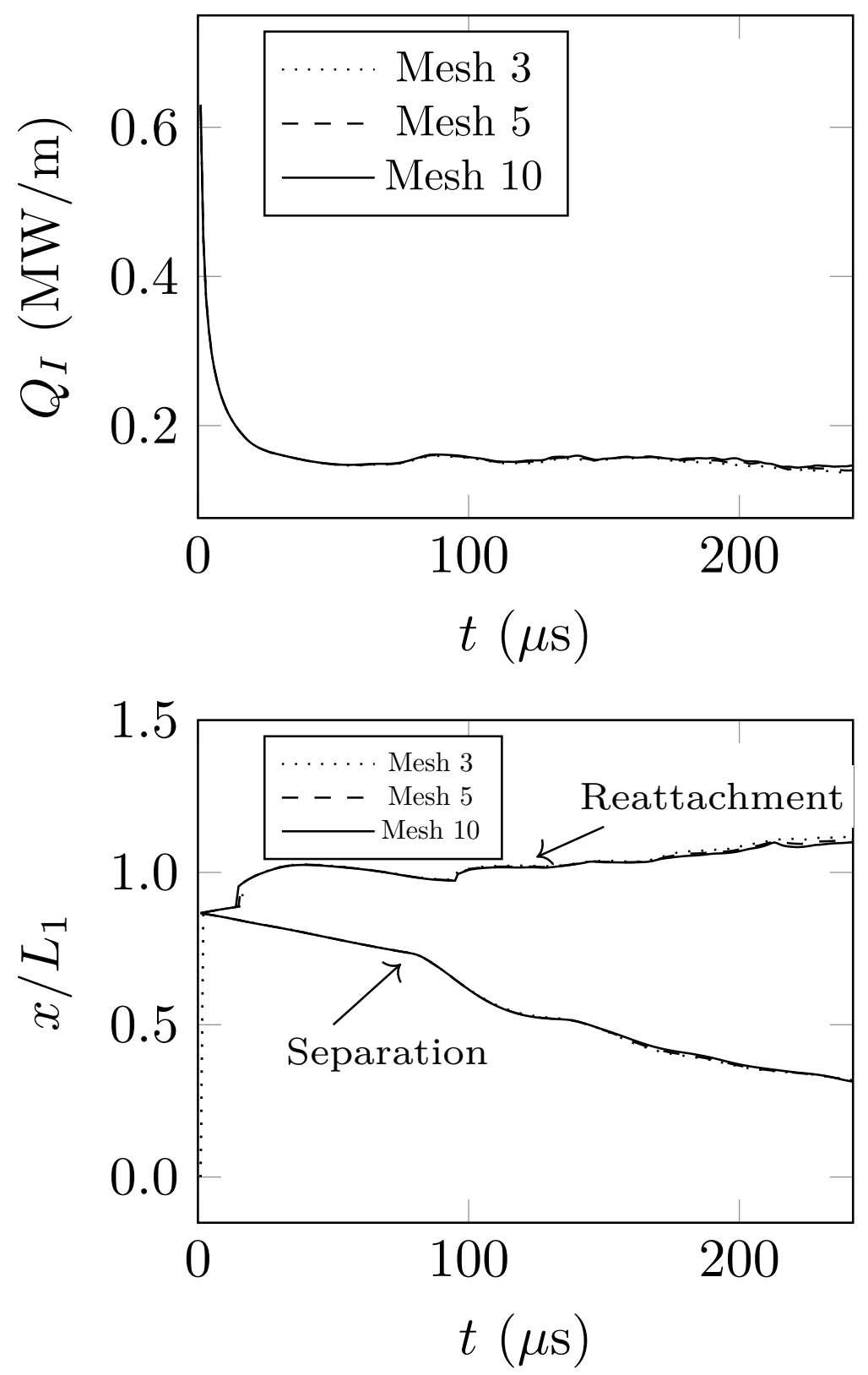

Figure 3: Integral heat transfer (top), and separation and reattachment locations (bottom) over time for the N8 case with three different meshes. 

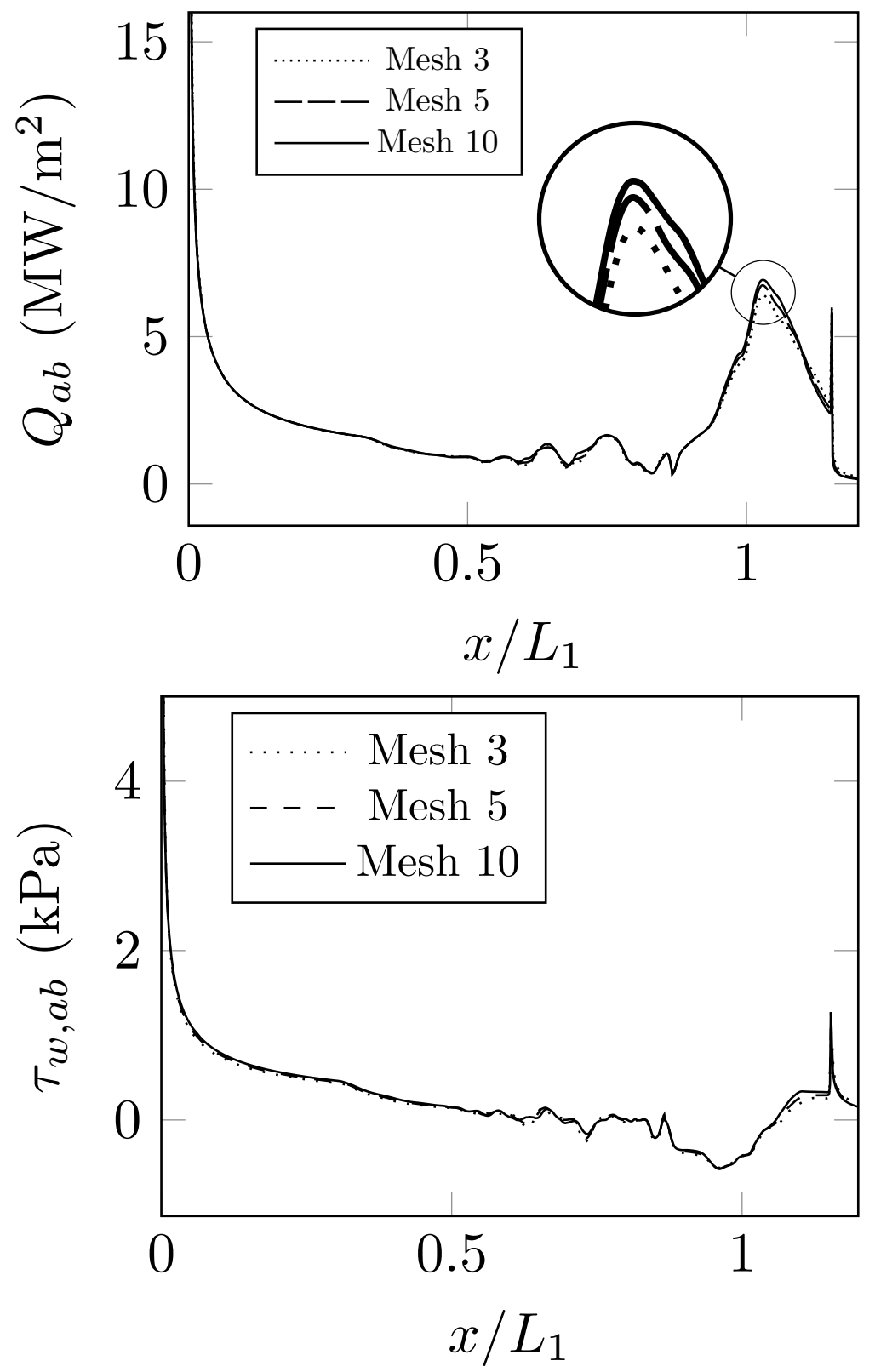

Figure 4: Time averaged heat transfer (top) and wall shear stress (bottom) for the N8 case and three different meshes, from $t_{a}=50 \mu \mathrm{s}$ to $t_{b}=242 \mu \mathrm{s}$. 


\subsection{Low enthalpy}

145

The density gradient magnitude contours of the N2 case at two different times are shown in figure 5. As in the mesh convergence study, the separation point moves upstream along time. A number of vortices appear within the detached boundary layer, which has not been reported in the experiment. Each one of these structures seems to produce its own separation and reattachment shock-waves, which merge and advance towards the first separation wave. These features have been reported in other CFD simulations such as Komives et al. [18]. In close agreement to the experimental reference, a shock-wave emerging from the triple point impinges on the aft wedge.

Figure 6 provides the measured and predicted heat transfer for the low enthalpy nitrogen case. Some of the most accurate results from [16] are also included for comparison. It must be noted that previous studies provided data at specific times, even though the experimental measurements were time averaged over the viscous establishment time and test time.

The vortices generate oscillation of heat transfer values that are the main source of discrepancies with the reference in all cases. These oscillations are particularly important in the solution of Lani et al. (see Knight et al. [16]), which also heavily underestimates the heat transfer over the leading edge due to an early separation produced at $10 \mathrm{~mm}$ from the tip of the model. This distance is not reached by the separation point of our simulations and is attained by Komives outside of the experimental test time, at $t=$ $163.5 \mathrm{~ms}$ [16]. The peak heat transfer is over-estimated in all cases, with the reattachment point of Lani et al. (see Knight et al. [16]) located downstream of the experimental one. The shock impingement produces the last heat 

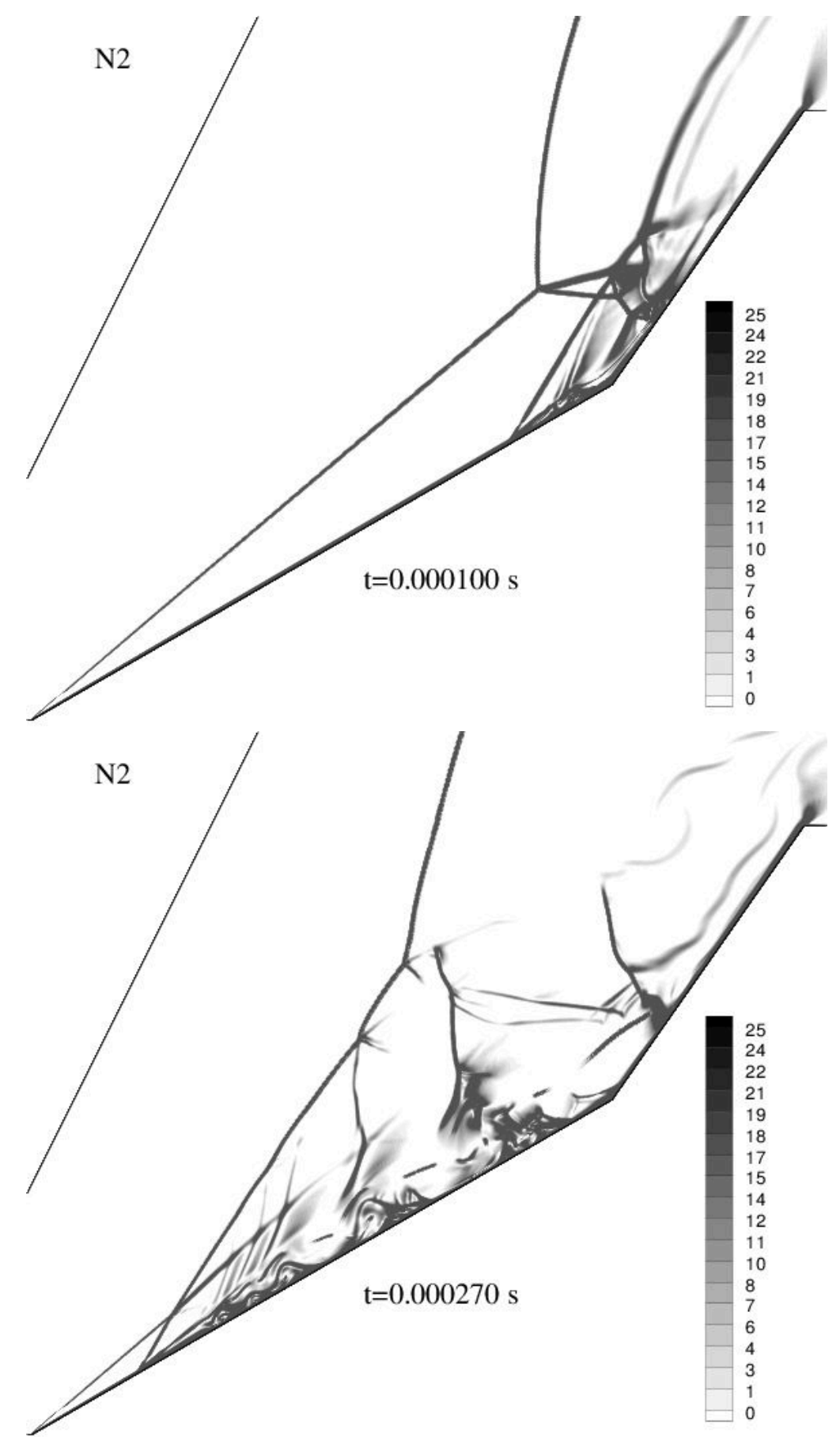

Figure 5: Density gradient magnitude contours at $100 \mu \mathrm{s}$ (top) and at $270 \mu \mathrm{s}$ (bottom). Legend header is omitted for a better view. 


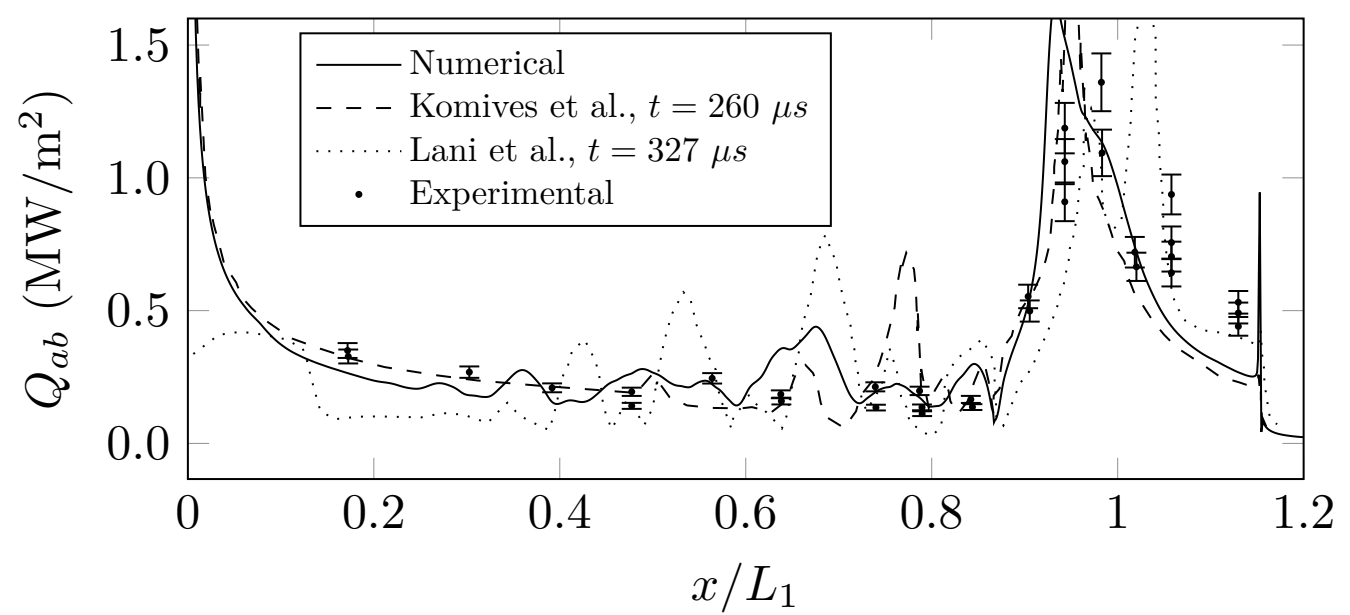

Figure 6: Mean heat transfer profile from $t_{a}=50 \mu \mathrm{s}$ to $t_{b}=327 \mu \mathrm{s}$ for the N2 case, compared with the numerical solutions of Komives et al. at $260 \mu s$ and Lani et al. at 327 $\mu s[16]$, together with the experimental data of [17].

transfer peak, which is much larger in our simulations than reported in the literature. This is common to the rest of the case and will be analysed later. Both in terms of trends and order of magnitude, the results can be deemed accurate.

In order to provide a full description of the evolution of surface heat transfer all over the geometry, figure 7 provides the instantaneous heat transfer at all points along time. The development of the vortical structures can be tracked with the local peaks that they produce. Reattachment remains around an almost constant position, and the shock impingement location is always at $x / L_{1}=1.1528$, after which heat transfer remains at a low level.

In the experiment, the viscous establishment times are defined as the time required by each gauge to measure their mean heat transfer value. For the low enthalpy nitrogen case, this value was around $150 \mu$ s for gauges close to 


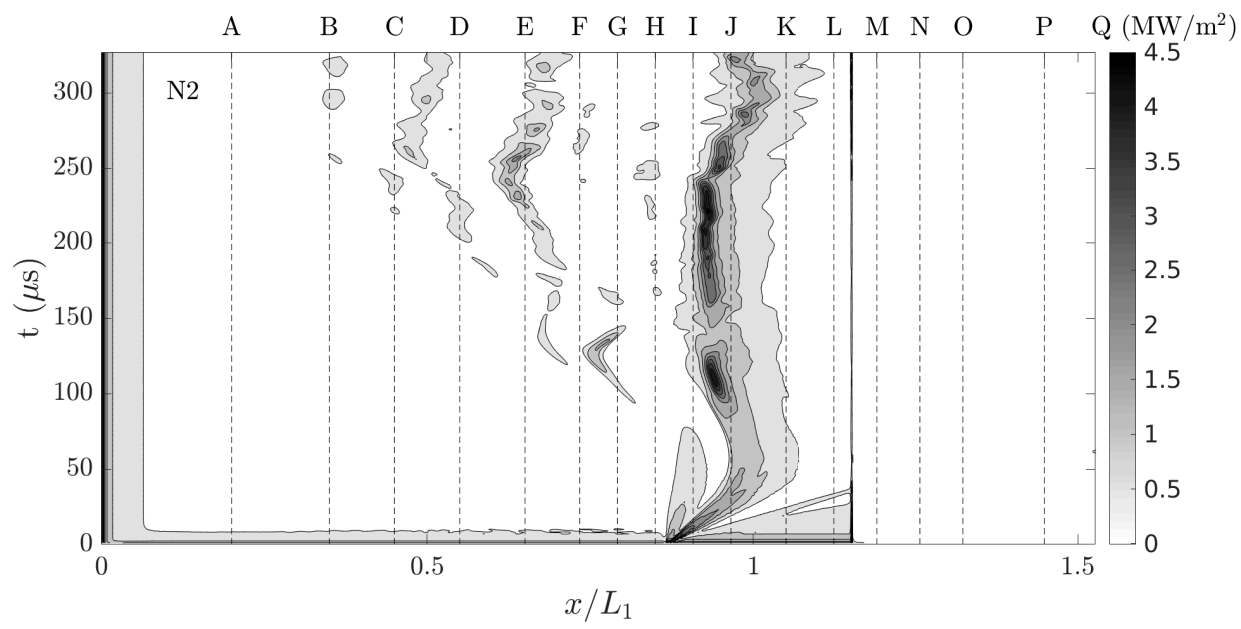

Figure 7: Heat transfer over the geometry along time for the N2 case. The experimental thermocouples have been placed on the top axis.

the reattachment region. In the simulation, however, steady heat transfer profiles are not obtained at any gauge location as the case is completely unsteady, like other CFD studies [16].

Dissociation of nitrogen was not achieved and thermochemical activity is irrelevant. Figure 8 provides the vibrational temperature contour, where a Kelvin-Helmholtz instability can be detected after the collision of two shockwaves, which can also be seen in the experimental images and is common to all cases.

\subsection{High enthalpy}

The nitrogen and air shock-waves at two different times are shown in figure 9 . The boundary layer is slightly smaller in the air case than in the nitrogen case.

The mean heat transfer profile for the nitrogen case is obtained in figure 


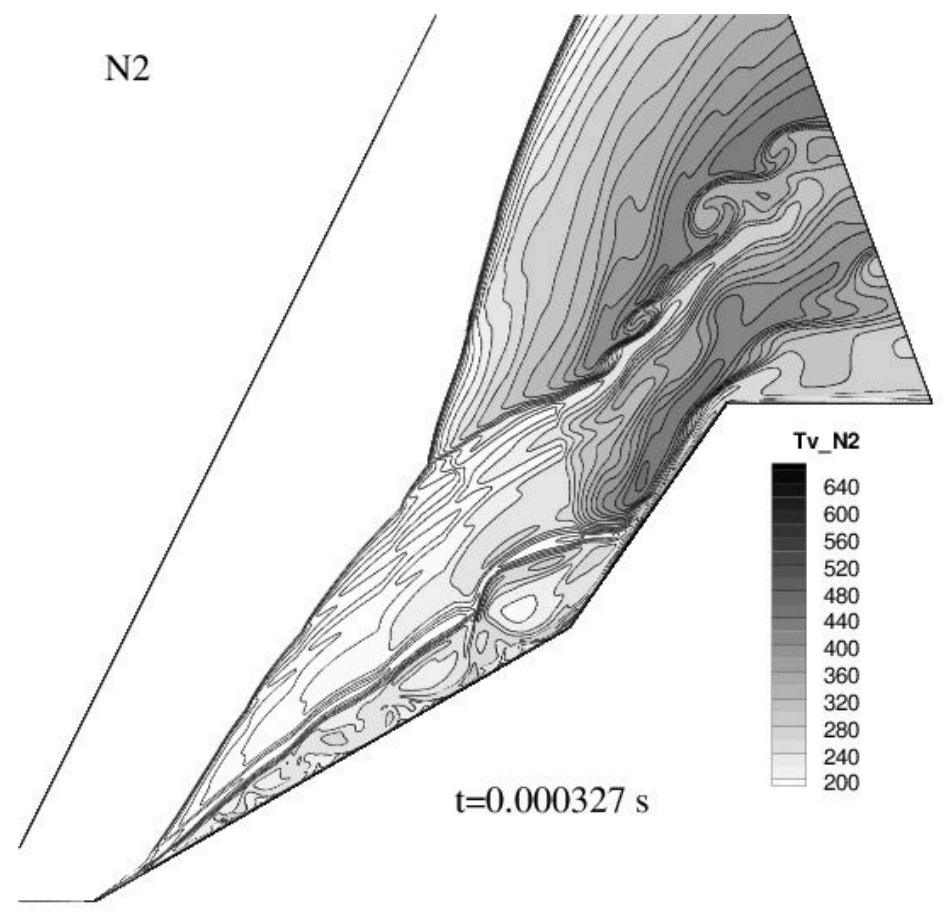

Figure 8: Vibrational temperature for the N2 case. A Kelvin-Helmholtz instability can be seen after the collision of two shock-waves in the post bow shock region. 
10. The best agreement with the experimental measurements is obtained by the steady-state simulations of Rosa et al. (see Knight et al. [16]), where transition at $x=29.5 \mathrm{~mm}$ was assumed. However, the results were found to be highly dependant upon the imposed location of transition. Our simulations provide accurate results when compared to other transient simulations. Tumuklu and Levin (see Knight et al. [16]) provided the best agreement with the experimental data among time-accurate simulations, using 3D nonequilibrium results at $t=100 \mu s$, although no separation on the forward wedge was obtained. The oscillations on the forward edge values have a lower relative impact than in the low enthalpy case due to the reduced time range used for the averaging process.

In the air case (figure 11), the results shown provided a very similar separation point at $x / L_{1} \approx 0.64$, however ours show substantial improvement of the prediction of the heat transfer peak. The simulation of Komives et al. gave the same location of the heat transfer peak but underestimated its magnitude, while the peak predicted by the 3D calculations of Lani et al. (see Knight et al. [16]) did not reach the experimental position within the test time.

The instantaneous heat transfer for the nitrogen case is shown in figure 12 and the air values are obtained in figure 13. Unlike the low enthalpy case, the reattachment point moves towards the impingement location, and the reattachment peaks due to vortical structures are not visible due to the higher values of the other peaks, which are one order of magnitude higher than those from N2.

The improvement of the prediction of the reattachment heat transfer 

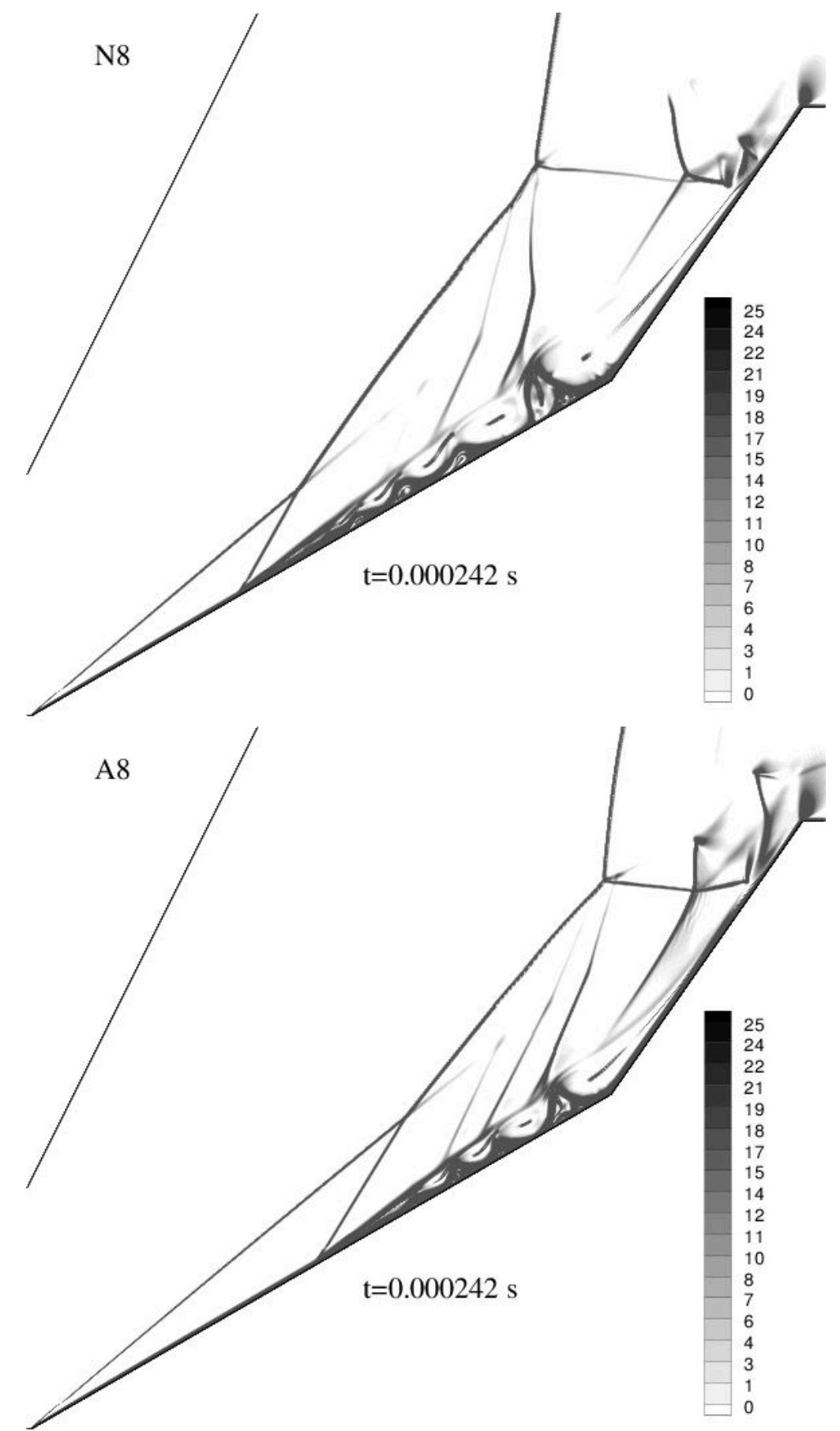

Figure 9: Density gradient magnitude contours at $242 \mu$ s for the N8 (top) and the A8 (bottom) cases. 


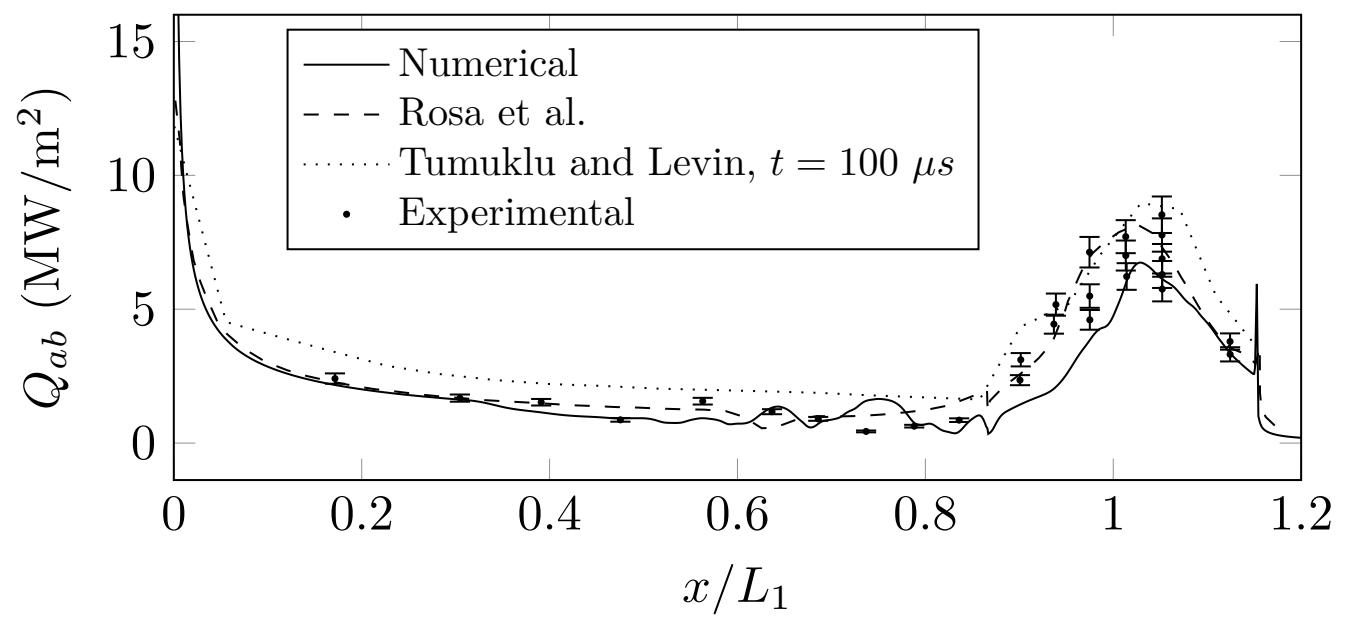

Figure 10: Mean heat transfer profile from times $50 \mu$ s to $242 \mu$ s for the N8 case, compared with the numerical solutions of Rosa et al., and Tumuklu and Levin at $100 \mu s$ [16], together with the experimental data of [17].

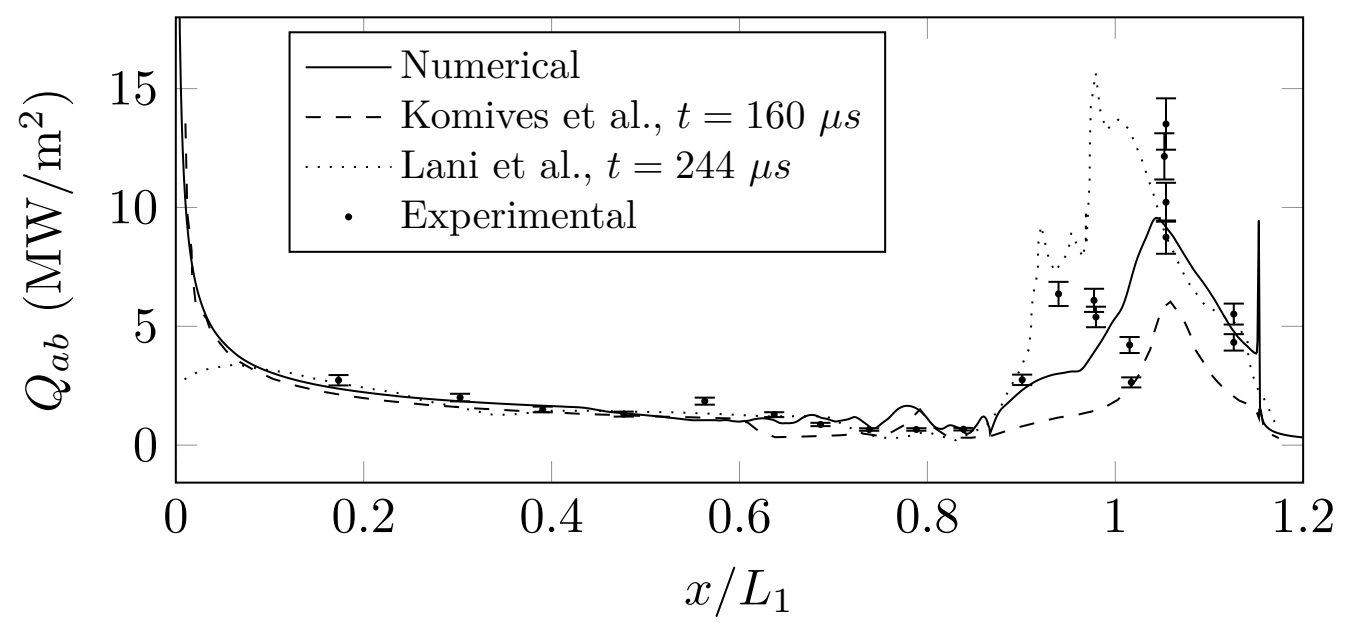

Figure 11: Mean heat transfer profile from times $50 \mu$ s to $242 \mu$ s for the A8 case, compared with the numerical solutions of Komives et al. at $160 \mu s$, and Lani et al. at $244 \mu s$ [16], together with the experimental data of [17]. 


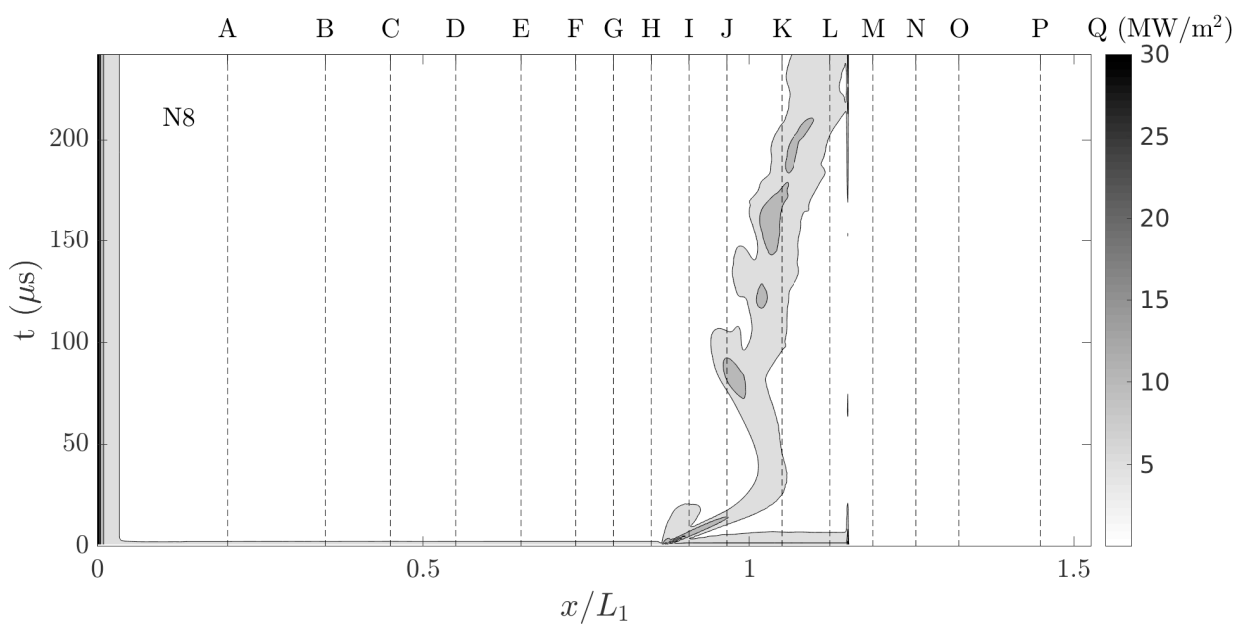

Figure 12: Heat transfer over the geometry along time for the N8 case.

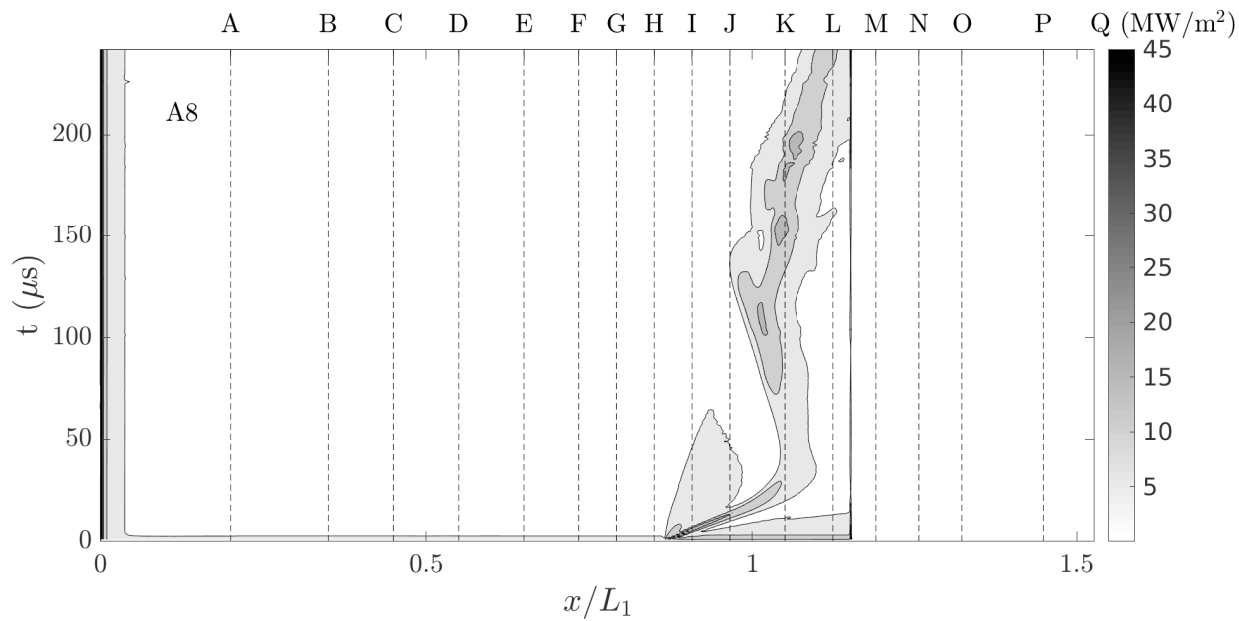

Figure 13: Heat transfer over the geometry along time for the A8 case. 
220

peak observed in the air case might be due to the non-equilibrium effects calculated. Figure 14 shows the vibrational temperature to translationalrotational temperature ratio, together with the absolute translational-rotational temperature contours for the A8 case at $t=242 \mu \mathrm{s}$. The flow is in thermal equilibrium after the bow shock, even though the NO spectroscopy of Swantek [38] at $t=100 \mu s$ revealed thermal non-equilibrium; this is similar to the solution obtained by [22]. However, in our case, the forward wedge flow shows a more important thermal non-equilibrium due to the value of the vibrational temperature in that region, as seen in figure 15, although the separated flow is close to thermal equilibrium. The maximum mass fractions of atomic oxygen and nitric oxide obtained at test time were $8.5 \%$ and $14 \%$, respectively, with the maximum of NO located close to the shear layer boundary as shown in figure 15 .

The effect of thermal non-equilibrium on the wall heat transfer profile is explained as follows. Molecules vibrationally excited are more likely to dissociate [39], leading to a higher rate of endothermic chemical reactions in the air flow that will lead to a thinner boundary layer, which increase the heat transfer peaks as explained in [40]. If results of non-equilibrium effects in the simulations of [16] were available in the literature, we could study if the higher accuracy obtained in the high enthalpy air case could be due to differences in the vibrational temperature solutions.

Figure 16 provides the heat transfer peaks due to reattachment of the boundary layer and the impingement of a shock wave on the surface of the geometry, where the heat transfer considering air flow follows a similar trend than the one obtained with nitrogen flow, but with a higher magnitude. The 

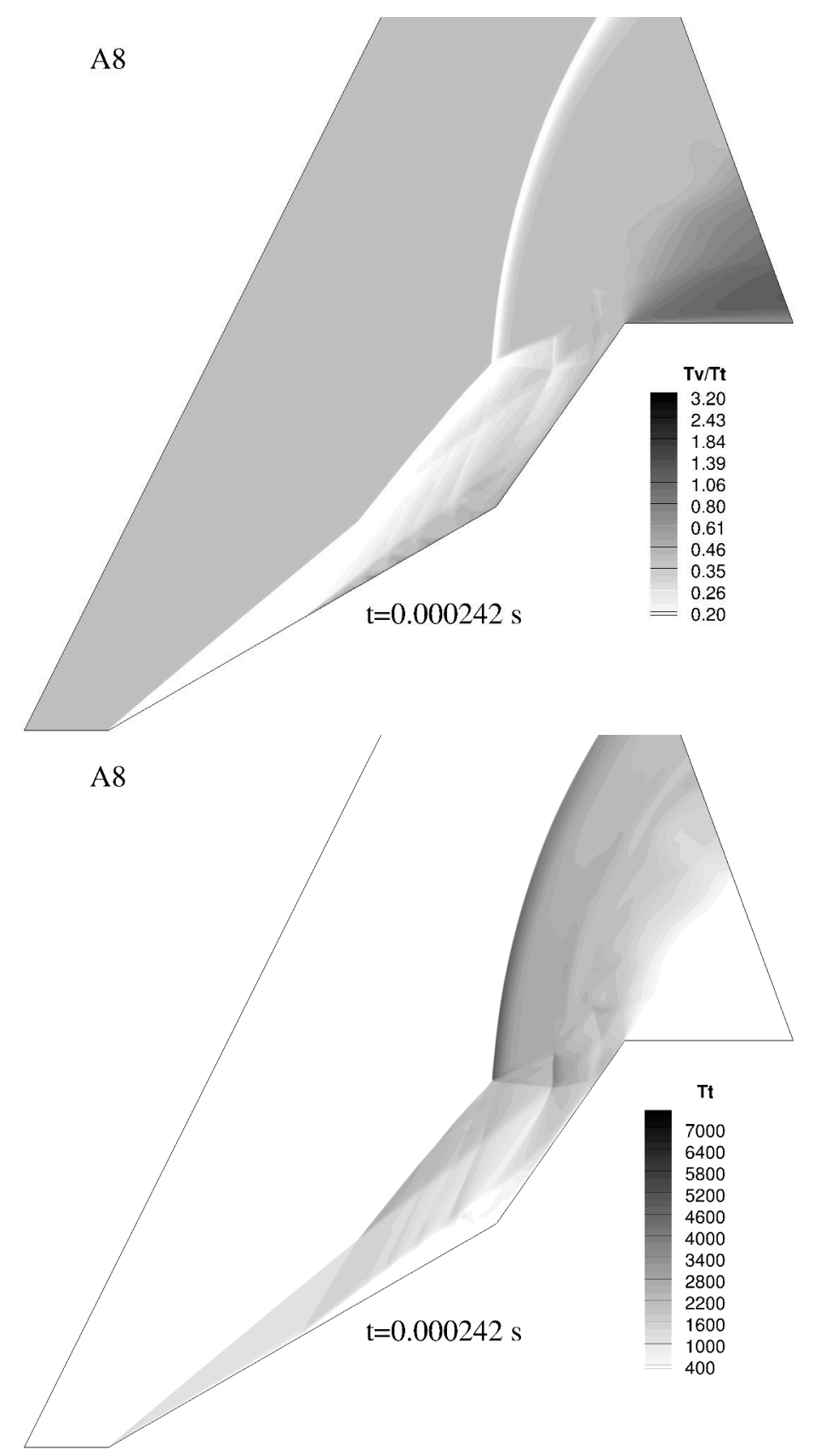

Figure 14: Vibrational temperature to translational-rotational temperature ratio (top) and translational-rotational temperature (bottom) contours for the high enthalpy air case at $t=242 \mu s$. 

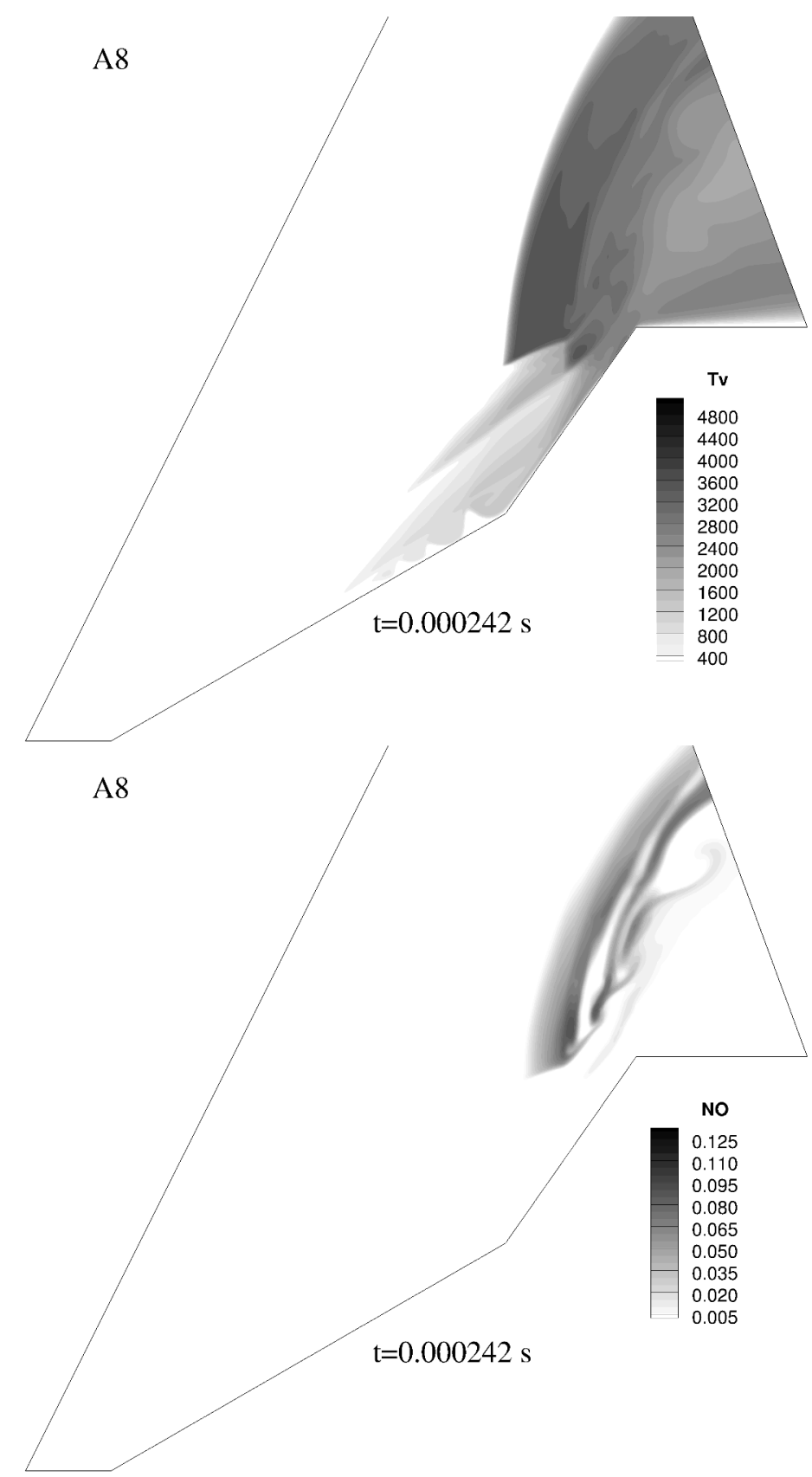

Figure 15: Vibrational temperature (top) and NO mass fraction (bottom) contours for the high enthalpy air case at $t=242 \mu s$. 
245 impingement peaks rise after $150 \mu \mathrm{s}$ as reattachment joins impingement. In the experimental reference, maximum viscous establishment times for both nitrogen and air cases were around $120 \mu \mathrm{s}$, and again the simulations provided an unsteady flow. In previous studies, little attention is paid to this feature as its value is considerably smaller than in our results. 

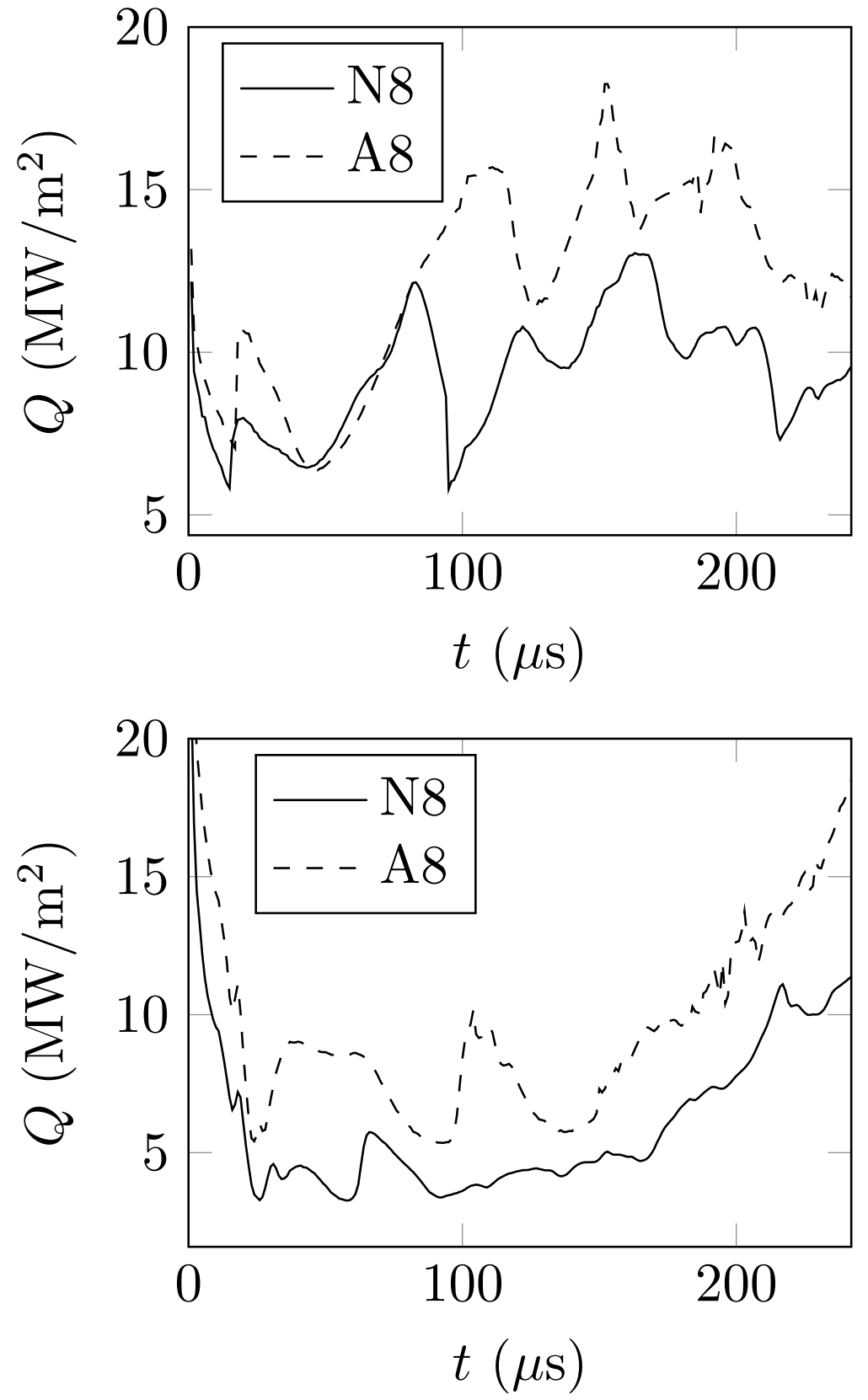

Figure 16: Comparison of reattachment (top) and impingement (bottom) heat transfer peaks. 


\section{Conclusions}

Time-accurate simulations using non-equilibrium equations of a hypersonic flow over a particular double wedge geometry were carried out using the application hy2Foam. The mean heat transfer profiles of all cases were accurately reproduced numerically, and a major improvement in the prediction of the reattachment heat transfer peak in the high enthalpy air case was observed. Parallel to this, substantial thermal non-equilibrium was obtained on the forward wedge flow, thus indicating that non-equilibrium modelling is essential for better prediction of the air wall heat transfer. Regarding the flow structure, hy2FOAM was also unable to predict the steady state within the time bracket considered, even with a nano scale time step, which indicates that perhaps simulations are required to run for much longer times. In the high enthalpy cases, the reattachment location moves downstream and merges the impingement of a shock wave on the surface. Both reattachment and impingement heat transfer peaks are unsteady with no apparent main frequency, and the latter is much higher than reported in the literature. Based upon these conclusions it is suggested that a more accurate thermal and chemical non-equilibrium model may have a significant impact on the simulation of such high enthalpy flows.

\section{Conflict of interest statement}

270 The authors declare there is no conflict of interest. 


\section{Acknowledgments}

The authors are grateful to Mr. Michael Knaggs from Cranfield HPC and Dr. Vincent Casseau for his constant support with hy2FOAM application. This research did not receive any specific grant from funding agencies in the

public, commercial, or not-for-profit sectors.

\section{References}

[1] R. MacCormack, B. Baldwin, A numerical method for solving the navierstokes equations with application to shock-boundary layer interactions, in: 13th Aerospace Sciences Meeting, 1975, p. 1.

[2] C. Hung, R. MacCormack, Numerical solutions of supersonic and hypersonic laminar flows over a two-dimensional compression corner, in: 13th Aerospace Sciences Meeting, 1975, p. 2.

[3] M. Holden, Shock wave-turbulent boundary layer interaction in hypersonic flow, AIAA paper (1972) 72-74.

[4] D. Rudy, J. Thomas, A. Kumar, P. Gnoff, S. Chakravarthy, A validation study of four navier-stokes codes for high-speed flows, in: 20th Fluid Dynamics, Plasma Dynamics and Lasers Conference, 1989, p. 1838.

[5] Y. Zhu, C. Lee, X. Chen, J. Wu, S. Chen, M. Gad-El-Hak, Newly identified principle for aerodynamic heating in hypersonic flows, Journal of Fluid Mechanics 855 (2018) 152-180, cited By 0. doi:10.1017/jfm.2018.646.

URL https://www.scopus.com/inward/record.uri?eid=2-s2. 
0-85053351245\&doi=10 $\cdot 1017 \% 2 \mathrm{f} \mathrm{fm} .2018 \cdot 646 \&$ partner ID $=40 \& \mathrm{md} 5=$ b50a8478466a3e1bb5a849178f9a249c

[6] S.-S. Chen, C. Yan, K. Zhong, H.-C. Xue, E.-L. Li, A novel flux splitting scheme with robustness and low dissipation for hypersonic heating prediction, International Journal of Heat and Mass Transfer 127 (2018) 126137, cited By 0. doi:10.1016/j.ijheatmasstransfer.2018.06.121. URL https://www. scopus. com/inward/record.uri?eid=2-s2. 0-85049757109\&doi $=10.1016 \% 2 f j$. i jheatmasstransfer. 2018.06 . 121\&partnerID=40\&md5=a9af53585f9a52977f85d7d9c7f1d2c9

[7] H. Xiao, Q. He, Aero-heating in hypersonic continuum and rarefied gas flows, Aerospace Science and Technology 82-83 (2018) 566 - 574. doi:https://doi.org/10.1016/j.ast.2018.09.036. URL http://www.sciencedirect.com/science/article/pii/ S1270963818314779

[8] M. Ferraiuolo, R. Scigliano, A. Riccio, E. Bottone, M. Rennella, Thermo-structural design of a ceramic matrix composite wing leading edge for a re-entry vehicle, Composite Structures 207 (2019) 264-272, cited By 0. doi:10.1016/j.compstruct.2018.09.024.

URL https://www.scopus.com/inward/record.uri?eid=2-s2. 0-85054003078\&doi=10.1016\%2f j . compstruct . 2018.09.024\& partnerID=40\&md5=34f 0882 c0acc068cee3dd0af $980 \mathrm{fedcd}$

[9] Z. A. Rana, B. Thornber, D. Drikakis, Dynamics of sonic hydrogen jet injection and mixing inside scramjet combustor, Engineering Applications of Computational Fluid Mechanics 7 (1) (2013) 13-39. arXiv: 
https://doi.org/10.1080/19942060.2013.11015451, doi:10.1080/ 19942060.2013 .11015451$.

URL https://doi.org/10.1080/19942060.2013.11015451

320

325

330

335

[10] Z. A. Rana, B. Thornber, D. Drikakis, On the importance of generating accurate turbulent boundary condition for unsteady simulations, Journal of Turbulence 12 (2011) N35. arXiv:https://doi.org/10.1080/ 14685248.2011.613836, doi:10.1080/14685248.2011.613836.

URL https://doi.org/10.1080/14685248.2011.613836

[11] H. Su, J. Wang, F. He, L. Chen, B. Ai, Numerical investigation on transpiration cooling with coolant phase change under hypersonic conditions, International Journal of Heat and Mass Transfer 129 (2019) 480-490, cited By 0. doi:10.1016/j.ijheatmasstransfer.2018.09.123. URL https://www.scopus.com/inward/record.uri?eid=2-s2. 0-85054297980\&doi=10.1016\%2fj . i jheatmasstransfer. 2018.09 . 123\&partnerID $=40$ \&md5 $=5$ e59eb2fbf $4 \mathrm{afe} 4 \mathrm{a} 27 \mathrm{dbd} 7770 \mathrm{c} 88 \mathrm{~d} 7 \mathrm{cf}$

[12] S. D. Giorgio, D. Quagliarella, G. Pezzella, S. Pirozzoli, An aerothermodynamic design optimization framework for hypersonic vehicles, Aerospace Science and Technology 84 (2019) 339 - 347. doi:https://doi.org/10.1016/j.ast.2018.09.042.

URL http://www.sciencedirect.com/science/article/pii/ S1270963818301305

[13] K. Ye, Z. Ye, C. Li, J. Wu, Effects of the aerothermoelastic deformation on the performance of the three-dimensional hypersonic inlet, Aerospace Science and Technologydoi:https: 
//doi.org/10.1016/j.ast.2018.11.015.

URL http://www.sciencedirect.com/science/article/pii/ S1270963817312002

[14] D. Knight, Rto wg 10-test cases for cfd validation of hypersonic flight, in: 40th AIAA Aerospace Sciences Meeting \& Exhibit, 2002, p. 433.

[15] D. Knight, J. Longo, D. Drikakis, D. Gaitonde, A. Lani, I. Nompelis, B. Reimann, L. Walpot, Assessment of cfd capability for prediction of hypersonic shock interactions, Progress in Aerospace Sciences 48 (2012) $8-26$.

[16] D. Knight, O. Chazot, J. Austin, M. A. Badr, G. Candler, B. Celik, D. de Rosa, R. Donelli, J. Komives, A. Lani, et al., Assessment of predictive capabilities for aerodynamic heating in hypersonic flow, Progress in Aerospace Sciences 90 (2017) 39-53.

[17] A. Swantek, J. Austin, Heat transfer on a double wedge geometry in hypervelocity air and nitrogen flows, in: 50th AIAA Aerospace Sciences Meeting including the New Horizons Forum and Aerospace Exposition, 2012, p. 284.

[18] J. R. Komives, I. Nompelis, G. V. Candler, Numerical investigation of unsteady heat transfer on a double wedge geometry in hypervelocity flows, in: 44th AIAA Fluid Dynamics Conference, 2014, p. 2354.

[19] M. A. Badr, D. D. Knight, Shock wave laminar boundary layer interaction over a double wedge in a high mach number flow, in: 52nd Aerospace Sciences Meeting, 2014, p. 1136. 
[20] V. N. Patil, D. A. Levin, S. F. Gimelshein, J. M. Austin, Study of shockshock interactions for the het facility double wedge configuration using the dsmc approach, in: 43rd AIAA Fluid Dynamics Conference, 2013, p. 3202.

[21] A. S. Durna, M. El Hajj Ali Barada, B. Celik, Shock interaction mechanisms on a double wedge at mach 7, Physics of Fluids 28 (9) (2016) 096101.

[22] A. Khraibut, S. Gai, Flow steadiness over a double wedge at mach 7 including effect of trailing edge expansion, in: 22nd AIAA International Space Planes and Hypersonics Systems and Technologies Conference, 2018, p. 5388.

375

[23] OpenFOAM, http://www.openfoam.org/, accessed: 20-08-2018 (2018).

[24] V. Casseau, D. E. Espinoza, T. J. Scanlon, R. E. Brown, A twotemperature open-source cfd model for hypersonic reacting flows, part two: Multi-dimensional analysis, Aerospace 3 (4) (2016) 45.

[25] V. Casseau, R. C. Palharini, T. J. Scanlon, R. E. Brown, A twotemperature open-source cfd model for hypersonic reacting flows, part one: Zero-dimensional analysis, Aerospace 3 (4) (2016) 34.

[26] M. S. Holden, T. P. Wadhams, Code validation study of laminar shock/boundary layer and shock/shock interactions in hypersonic flow, part a: Experimental measurements, AIAA paper 1031 (2001) 2001. 
[27] L. Scalabrin, I. Boyd, Numerical simulation of weakly ionized hypersonic flow for reentry configurations, in: 9th AIAA/ASME Joint Thermophysics and Heat Transfer Conference, 2006, p. 3773.

[28] V. Casseau, An open-source cfd solver for planetary entry, Ph.D. thesis, University of Strathclyde (2017).

[29] W. G. Vincenti, C. H. Kruger, Introduction to physical gas dynamics, Vol. 246, Wiley New York, 1965.

[30] R. C. Millikan, D. R. White, Systematics of vibrational relaxation, The Journal of chemical physics 39 (12) (1963) 3209-3213.

[31] C. Park, Review of chemical-kinetic problems of future nasa missions. i-earth entries, Journal of Thermophysics and Heat transfer 7 (3) (1993) $385-398$.

[32] C. Park, Nonequilibrium hypersonic aerothermodynamics.

[33] C. Wilke, A viscosity equation for gas mixtures, The journal of chemical physics 18 (4) (1950) 517-519.

[34] B. Armaly, K. Sutton, Viscosity of multicomponent partially ionized gas mixtures, in: 15th Thermophysics Conference, 1980, p. 1495.

[35] F. G. Blottner, M. Johnson, M. Ellis, Chemically reacting viscous flow program for multi-component gas mixtures., Tech. rep., Sandia Labs., Albuquerque, N. Mex. (1971). 
[36] A. Kurganov, S. Noelle, G. Petrova, Semidiscrete central-upwind schemes for hyperbolic conservation laws and hamilton-jacobi equations, SIAM Journal on Scientific Computing 23 (3) (2001) 707-740.

[37] C. J. Greenshields, H. G. Weller, L. Gasparini, J. M. Reese, Implementation of semi-discrete, non-staggered central schemes in a colocated, polyhedral, finite volume framework, for high-speed viscous flows, International journal for numerical methods in fluids 63 (1) (2010) 1-21.

[38] A. Swantek, The role of aerothermochemistry in double cone and double wedge flows, Ph.D. thesis, University of Illinois at Urbana-Champaign (2012).

[39] C. Park, Modeling of hypersonic reacting flows, in: Advances in Hypersonics, Springer, 1992, pp. 104-127.

[40] S. Mallinson, S. Gai, N. Mudford, Upstream influence and peak heating in hypervelocity shock wave/boundary-layer interaction, Journal of propulsion and power 12 (5) (1996) 984-990. 
2019-07-12

\title{
Computational investigations into heat transfer over a double wedge in hypersonic flows
}

\author{
Expósito, Diego
}

Elsevier

Exposito D, Rana ZA. (2019) Computational investigations into heat transfer over a double wedge in hypersonic flows. Aerospace Science and Technology, Volume 92, September 2019, pp. 839-846

https://doi.org/10.1016/j.ast.2019.07.013

Downloaded from Cranfield Library Services E-Repository 